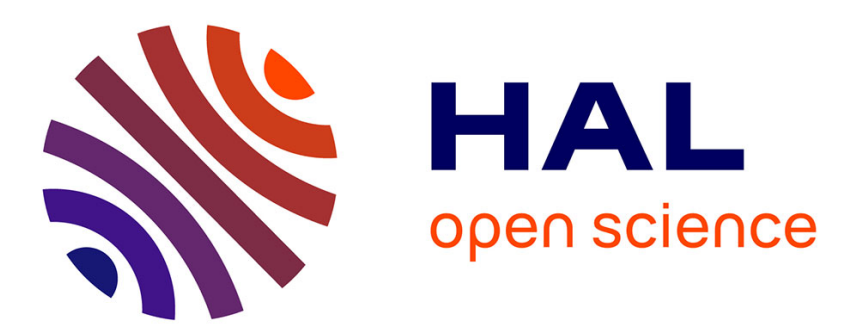

\title{
COMPARISON OF RELAXATION STUDIES BY MÖSSBAUER EMISSION TRANSMISSION AND SCATTERING EXPERIMENTS
}

\author{
F. Hartmann-Boutron
}

\section{- To cite this version:}

F. Hartmann-Boutron. COMPARISON OF RELAXATION STUDIES BY MÖSSBAUER EMISSION TRANSMISSION AND SCATTERING EXPERIMENTS. Journal de Physique Colloques, 1976, 37 (C6), pp.C6-71-C6-72. 10.1051/jphyscol:1976617 . jpa-00216692

HAL Id: jpa-00216692

https://hal.science/jpa-00216692

Submitted on 1 Jan 1976

HAL is a multi-disciplinary open access archive for the deposit and dissemination of scientific research documents, whether they are published or not. The documents may come from teaching and research institutions in France or abroad, or from public or private research centers.
L'archive ouverte pluridisciplinaire HAL, est destinée au dépôt et à la diffusion de documents scientifiques de niveau recherche, publiés ou non, émanant des établissements d'enseignement et de recherche français ou étrangers, des laboratoires publics ou privés. 


\title{
COMPARISON OF RELAXATION STUDIES BY MÖSSBAUER EMISSION TRANSMISSION AND SCATTERING EXPERIMENTS
}

\author{
F. HARTMANN-BOUTRON \\ Laboratoire de Spectrométrie Physique \\ BP 53, 38041 Grenoble Cedex, France
}

\begin{abstract}
Résumé. - Cette communication résume les résultats obtenus dans plusieurs articles récents $[1,2,3]$.

Abstract. - This communication summarizes the results obtained in several recent papers $[1,2,3]$.
\end{abstract}

1. General comparison of the three techniques in the absence of relaxation [1]. - 1) In an emission experiment we have a radioactive cascade of which the Mössbauer $\gamma$ ray is the last step. The successive decays are due to spontaneous emission induced by the fluctuations of the vacuum, which have a white spectrum; the decays are therefore instantaneous. The resulting Mössbauer lineshape $I(\omega)$ is fairly simple (eq. (1) of [1]), with a clear physical interpretation.

2) In an absorption experiment one measures the imaginary part of the refraction index of the absorber, which is proportional to the average value of the forward scattering amplitude (eq. (25), (34), (35) of [1]).

3) Finally the scattering signal, which involves the average of the square of the scattering amplitude, corresponds to an induced absorption followed by spontaneous emission. However, since the linewidth of the incident photon is comparable to the width of the excited Mössbauer state, these processes are not well separated in time and this leads to complicated formulas (eq. (51), (52) of [1]). In addition there may be some difficulties related to interference and thickness effects, which have been discussed by other authors [4].

2. Introduction of relaxation [2]. - This is most conveniently done within the Liouville formalism, according to the prescriptions of Appendix I of [5].

1) In emission the Mössbauer lineshape $I(\omega)$ (eq. (6), (7) of [2]) involves two Liouville matrices $\mathrm{L}_{1}$ and $\mathrm{L}_{2}$ which describe respectively the evolution of the nuclear operator $\mathbf{T}$ responsible for the Mössbauer transition, and the evolution of the electronuclear density matrix $\sigma$ of the excited Mössbauer state $I$ between radioactive feeding and radioactive decay. $L_{1}$ gives rise to the line profile anomalies observed in standard experiments, while the role of $\mathrm{L}_{2}$ is more subtle. The initial density matrix $\sigma_{I}^{\text {in }}$ just after feeding by spontaneous emission is diagonal; if the relaxation has simple properties, $\sigma$ remains diagonal and one can obtain its average value at the time of $\gamma$ emission, $\sigma_{I}(1 / \Gamma)$, corresponding to $\mathrm{L}_{2}$, from standard rate equations for the populations $[6,7]$. Then the reorientation effects associated with $\sigma_{I}(1 / \Gamma)$ will be most important if the relaxation time inside $I$ is comparable to the nuclear lifetime $\tau_{\mathrm{n}}$. These population effects may play a role in three situations : - Hyperfine relaxation at very low temperatures ( $k_{\mathrm{B}} T \sim$ hyperfine hamiltonian), where they give rise to line intensity anomalies. This was discussed in $[6,7]$.

- Electronic rearrangement following a $\beta$ transition, which was considered in $[8,9]$. However these authors use a formula in which the average electronuclear density matrix $\sigma_{I}(1 / \Gamma)$ of state $I$ is replaced by the initial density matrix $\sigma_{I}^{\text {in }}$. This leads them to write that in order to attain Boltzmann equilibrium before $\gamma$ emission the rearrangement time must be short compared to the hyperfine period, instead of the correct condition that it be short compared to the nuclear lifetime $\tau_{n}$ [3]. If this last condition is not fulfilled (incomplete rearrangement), one could expect to see, in the Mössbauer spectrum, a contribution corresponding to electronic excited states out of thermal equilibrium.

- Formation of a Kondo polarization cloud around a localized electronic spin. Here too the build up time must be short compared with the nuclear lifetime (not with the hyperfine period as assumed in [10]). It is shown in ref. [3] that this condition is indeed fulfilled for $\mathrm{YbAu}$ at $0.3 \mathrm{~K}$ [7].

2) In absorption, since the density matrix of the ground state $I_{\mathrm{g}}$ is at thermal equilibrium, $I(\omega)$ contains only one Liouville matrix of the type $\mathrm{L}_{1}$ (eq. (3), (5) of [2]). When possible, the comparison between emission and absorption spectra would be a good way to check the existence or non existence of incomplete electronic rearrangement effects after a $\beta$ decay, as they would occur only in the first case. 
3) In the case of scattering [11], $I(\omega)$ is the sum of three terms $I_{1}, I_{2}, I_{3}$, each of which is a product of three Liouville matrices (eq. (8), (9) of [2]). It seems that the only simple situation is that where relaxation effects are small with respect to the hyperfine interactions and comparable to the lifetime broadening $1 / \tau_{\mathrm{n}}$ (same condition as for population effects in a source). In this case it can be shown [2] that the frequency of the scattered light corresponding to $I_{1}$ can only differ from the incident frequency by the hyperfine intervals of the ground state (Rayleigh and Raman scattering). On the contrary, for adequate choice of the incident frequency, $I_{2}+I_{3}$ correspond to selective excitation of a particu- lar excited hyperfine substate $f$; then, if relaxation produces a redistribution in the excited state $I$, the scattered spectrum corresponding to $I_{2}+I_{3}$ will contain, in addition to lines of the Rayleigh and Raman types, new lines originating from other excited substates $f^{\prime}$. However, only comparison of the integrated areas of the Rayleigh and Raman lines on the one hand, and of the new lines on the other hand can give information on relaxation. In conclusion it seems that the main interest of scattering lies in studies of slow relaxation (relaxation time $\sim \tau_{\mathrm{n}}$ ) at thermal equilibrium and finite temperatures, as they cannot be done by emission or absorption techniques.

\section{References}

[1] Hartmann-Boutron, F., J. Physique 37 (1976) 537.

[2] Hartmann-Boutron, F., J. Physique 37 (1976) 549.

[3] Hartmann-Boutron, F., Ann. de Phys. 9 (1975) 285-356.

[4] Balko, B., Hoy, G. R., Phys. Rev. B 10 (1974) 36, 4523.

[5] Hartmann-Boutron, F., Spanjaard, D., J. Physique 36 (1975) 307. After this paper was published, we discovered that a method similar to that of its Appendix I, had already been used in a different context by :

OMont, A., Sмith, S. W., CoOper, J., Astrophys. J. 175 (1972) 185.

[6] Hartmann-Boutron, F., Phys. Rev. B 10 (1974) 2113.
[7] GonZalez-Jimenez, F., Hartmann-Boutron, F., IMBERT, P., Phys. Rev. B 10 (1974) 2122.

[8] Hirst, L. L., Stöhr, J., Shenoy, G. K., Kalvius, G. M., Phys. Rev. Lett. 33 (1974) 198.

[9] STÖHR, J., Phys. Rev. B 11 (1975) 3559.

[10] Hrrst, L. L., J. Physique Collog. 35 (1974) C 6-21.

[11] Relaxation effects in Mössbauer scattering have already been studied in ref. [4] and also by Afanasev, A. M., Gorobchenko, V. D., Sov. Phys. J. E. T. P. 40 (1974) 1114. However these last authors assume a monochromatic irradiation while the finite linewidth of the incident $\gamma$ ray is an essential complication of the problem. 